\title{
Instructions to Authors
}

1. Submission. Articles written in English and not submitted for publication elsewhere, should be sent to Paul Salkovskis, Editor, Behavioural and Cognitive Psychotherapy, Department of Psychiatry, University of Oxford, Warneford Hospital, Oxford OX3 7JX, UK.

2. Manuscript preparation. Four complete copies of the manuscript must be submitted. Original figures should be supplied at the time of submission. Articles must be typed double-spaced throughout on standard sized paper (preferably A4) allowing wide margins all round. Where unpublished material, e.g. behaviour rating scales, therapy manuals, etc. is referred to in an article, copies should be submitted to facilitate review.

Manuscripts will be sent out for review exactly as submitted. Authors who want a blind review should mark two copies of their article "review copy" omitting from these copies details of authorship.

Abbreviations where used must be standard. The Système International (SI) should be used for all units; where metric units are used the SI equivalent must also be given. Probability values and power statistics should be given with statistic values and degrees of freedom [e.g. $F(1,34)=123 \cdot 07, P<0.001]$, but such information may be included in tables rather than the main text.

Spelling must be consistent within an article, either using British usage (The Shorter Oxford English Dictionary), or American usage (Webster's New Collegiate Dictionary). However, spelling in the list of references must be literal to each original publication.

Details of style not specified here may be determined by reference to the Publication Manual of the American Psychological Association or the style manual of the British Psychological Society.

Articles should conform to the following scheme:

(a) Title page. The title should phrase concisely the major issues. Author(s) to be given with departmental affiliations and addresses, grouped appropriately. A running head of no more than 40 characters should be indicated.

(b) Summary. This should summarize the article in no more than 200 words.

(c) Text. This should begin with an introduction, succinctly introducing the point of the paper to those interested in the general area of the journal. Attention should be paid to the Editorial Statement which appears in the January and July issues at the back of the Journal. References within the text should be given in the form Jones and Smith (1973). When there are three or up to and including five authors the first citation should include all authors; subsequent citations should be given as Williams et al. (1973). Authors with the same surname should be distinguished by their initials. The approximate positions of tables and figures should be indicated in the text. Footnotes should be avoided where possible.

(d) Reference note(s). A list of all cited unpublished or limited circulation material, numbered in order of appearance in the text, giving as much information as possible about extant manuscripts.

(e) References. All citations in the text should be listed in strict alphabetical order according to surnames. Muitiple references to the same author(s) should be listed chronologically, using $a, b$, etc., for entries within the same year. Formats for journal articles, books and chapters should follow these examples:

BECKER, M. R. and GrEEN, L. W. (1975). A family approach to compliance with medical treatment: A selective review of the literature. International Journal of Health Education 18, 173-182.

Thorp, R. G. and Wetzel, R. J. (1969). Behaviour Modification in the Natural Environment. New York: Academic Press.

Roskies, E. and Lazarus, R. S. (1980). Coping theory and the teaching of coping skills. In P. O. Davidson and S. M. Davidson (Eds). Behavioural Medicine: Changing Health Lifestyles. New York: Brunner/Mazel.

(f) Footnotes. The first, and preferably only, footnote will appear at the foot of the first page of each article, and subsequently may acknowledge previous unpublished presentation (e.g. dissertation, meeting paper) financial support, scholarly or technical assistance, or a change in affiliation. Its concluding (or only) paragraph must be the name and full mailing address of the author to whom reprint requests or other inquiries should be sent.

(g) Tables. Tables should be numbered and given explanatory titles.

(h) Figure captions. Numbered captions should be typed on a separate page.

(i) Figures. Original drawings or prints must be submitted for each line or half-tone illustration. Figures should be clearly labelled and be camera-ready wherever possible.

3. Proofs, Reprints and Copyright. Proofs of accepted articles will be sent to authors for the correction of printers' errors; author's alterations may be charged. Authors submitting a manuscript do so on the understanding that if it is accepted for publication exclusive copyright of the paper shall be assigned to the Association. In consideration of the assignment of copyright, 25 copies of each paper will be supplied. Further reprints may be ordered at extra cost; the reprint order form will be sent with the proofs. The publishers will not put any limitation on the personal freedom of the author to use material contained in the paper in other works. 


\section{Contents}

Stephen Rollnick \& William R Miller

What is Motivational Interviewing?

Jacqueline M J Withers

Motivation Interviewing: A Special Ethical Dilemma?

Martin Seager

Healing Psychology's Own Motivational Conflicts:

A Comment on Miller's "Etbics of Motivational Intervention"

William R Miller

The Ethics of Motivational Interviewing Revisited

Willi Ecker \& Johannes Engelkamp

Memory for Actions in Obsessive-Compulsive Disorder

Michael Bristow \& Jenifer Bright

Group Cognitive Therapy in Chronic Depression:

Results From Two Intervention Studies

Adrian B Kelly \& W Kim Halford

The Generalisation of Cognitive Behavioural Marital

Therapy in Behavioural, Cognitive \& Physiological Domains

\section{Clinical Section}

Alison Perry, Nicholas Tarrier \& Richard Morriss Identification of Prodromal Signs and Symptoms \& Early Intervention in Manic Depressive Psychosis Patients:

A Case Example

Book Reviews 